\title{
Maxillofacial Radiology 190
}

SADJ May 2021, Vol. 76 No. 4 p222

\section{$\mathbf{J}$ Walters}

The included images depict the most common lesion of odontogenic origin found in the maxillofacial region. What are the important radiological features and what would your provisional diagnosis be?
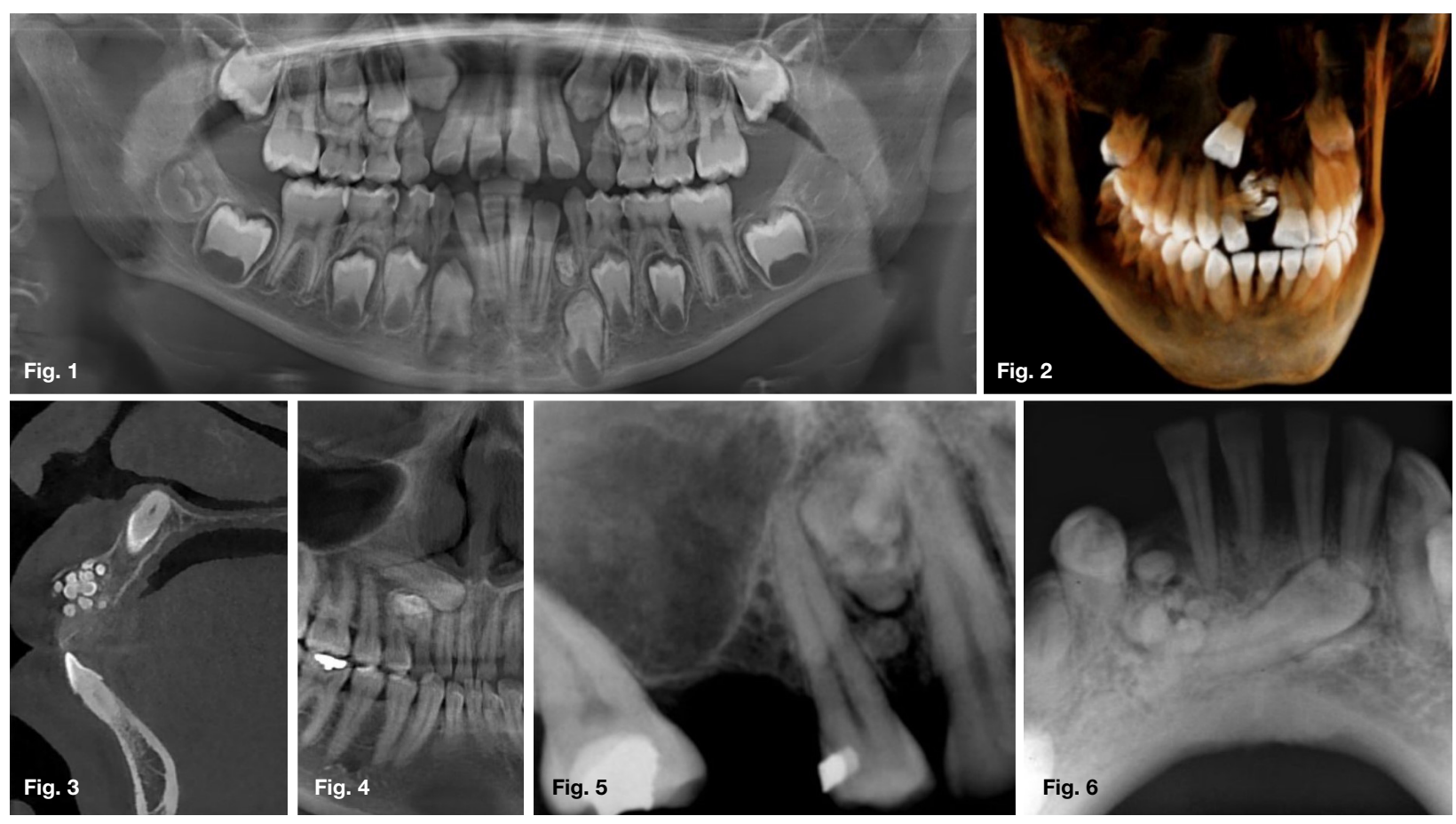

\section{INTERPRETATION}

The pantomograph (Figure 1) shows an incidental radiopaque mass in the 3rd quadrant. 3D MIP (Figure 2) and a sagittal CBCT slice (Figure 3 ) indicates an impaction of the maxillary central incisor. A reconstructed PAN (Figure 4) demonstrates a retained 53. With intraoral radiographs (Figure 5 and 6) demonstrating multiple miniature tooth-like structures. These are characteristic representations of compound odontomas.

In 1866 Broca introduced the French term odontome, which was initially used to refer to all tumours of odontogenic origin. The English term, odontoma, has subsequently become favoured over the former. Throughout the years' several classifications were presented. In 1971 the WHO defined two types, namely: compound, and complex. Originally known as benign mixed odontogenic tumours. Their tissues and respective cells appear morphologically normal, though lack structural arrangement. This deficiency gave rise to the opinion that they are hamartomatous malformations/lesions rather than true neoplasms.

Their growth potential is more restricted when compared to the complex odontoma. Thought to cease with the end of the tooth forming years. Clinical features are few, which may be limited to a mild firm asymptomatic swelling. Often incidentally discovered during routine radiographic examination or investigation of an unerupted permanent or retained primary tooth. Early lesions appear completely radiolucent. As they mature, internal features range from radiopaque specs to a mass, consisting of a few to several hundred miniature malformed tooth-like structures known as denticles. The encompassing connective tissue capsule appears as a peripheral narrow radiolucent zone, surrounded by a thin sclerotic border similar to a tooth crypt.

More than two-thirds of cases are diagnosed before the age of 20-years-old. Sex predilections are negligible. With a notable preference for the anterior jaws, particularly the maxilla. Treatment consists of conservative enucleation. Sparing adjacent unerupted teeth may be viable based on a favourable prognosis for eruption.

\section{References}

1. Langlais RP, Langland OE, Nortjé CJ. Diagnostic imaging of the jaws. Williams \& Wilkins. 1995.

2. Reichart P, Philipsen HP. Odontogenic tumors and allied lesions. Quintessence. 2004. 